\title{
PENTINGKAH KEANEKARAGAMAN HAYATI?: \\ Sebuah Landasan Teologis Memperjuangkan Keberlanjutan Biodiversitas
}

\section{Grace Son Nassa*}

\begin{abstract}
This research aims to construct a theological foundation on biodiversity as a guide used to defend biodiversity sustainability. The method used is literature study that focuses on three things, namely biodiversity crisis and forests as a home for biodiversity (land), the voice of the Bible on biodiversity and its relationship with humans, and the importance of the fight for biodiversity sustainability. The condition of biodiversity is critical. Meanwhile, the Bible emphasizes that biodiversity is a creation that is highly valued and blessed by God. In addition, humans are God's co-creators who should strive for the health of biodiversity sustainability for the sake of the sustainability of all life on earth. As humans are connected and tied to biodiversity, they are a part of biodiversity.
\end{abstract}

Keywords: Biodiversity, creation, sacramental, sustainability.

\begin{abstract}
Abstrak: Penelitian ini bertujuan membangun sebuah landasan teologis mengenai biodiversitas dan menjadikannya sebagai petunjuk dalam upaya memperjuangkan keberlanjutan biodiversitas. Metode yang digunakan adalah metode studi literatur yang difokuskan pada tiga hal, yakni krisis biodiversitas dan hutan sebagai rumah biodiversitas (darat), suara Alkitab mengenai biodiversitas dan relasinya dengan manusia, serta
\end{abstract}

* Penulis adalah dosen Sekolah Tinggi Agama Kristen Reformed Remnant Internasional. Penulis dapat dihubungi melalui email: graceson.nassa@gmail .com. 
pentingnya perjuangan bagi keberlanjutan biodiversitas. Kondisi biodiversitas sedang kritis. Sementara itu, Alkitab menekankan bahwa biodiversitas adalah ciptaan yang sangat dihargai dan diberkati Allah. Selain itu, manusia adalah cocreator Allah yang harusnya memperjuangkan dan mengupayakan keberlanjutan kesehatan biodiversitas demi keberlanjutan kehidupan bersama, dan karena terhubung dan terikat dengan biodiversitas, ia adalah kerabat biodiversitas.

Kata-kata kunci: Biodiversitas, ciptaan, sakramental, keberlanjutan.

\section{PENDAHULUAN}

Apa yang disampaikan Alkitab mengenai biodiversitas? Apakah penting keberlanjutan biodiversitas bagi manusia? Penelitian teologis sebelumnya mengenai biodiversitas banyak membahas tentang penafsiran kembali teks Alkitab terkait biodiversitas. Misalnya diskusi antara James A. Nash, James M. Childs, Jr., dan Celia Deane- Drummond. Nash mengangkat isu biodiversitas dan dikaitkan dengan suara Alkitab. Menurutnya, Alkitab sangat jelas dan lantang dalam menyuarakan serta memperjuangkan biodiversitas. la mengutip banyak ayat Alkitab dalam mendukung argumennya. ${ }^{1}$ Sebagai respons atas ide Nash tersebut, Childs, Jr. mengatakan bahwa masalah biodiversitas tidak dapat hanya dilihat dari pengutipan berbagai ayat Alkitab, melainkan juga perlu untuk menggunakan tradisi dan pengalaman gerejawi. Alkitab, tradisi, dan

1. James A. Nash, "The Bible vs. Biodiversity: The Case against Moral Argument from Scripture," Journal for the Study of Religion, Nature and Culture 3, no. 2 (Juni 2009): 213-37, diakses 26 September 2021, http://search.ebscohost. com/login.aspx?direct=true\&db=a6h\&AN=ATLA0001741316\&site=ehost-live. 
pengalaman harus dikombinasikan agar upaya memperjuangkan keberlanjutan biodiversitas dapat menyentuh ranah moralitas. ${ }^{2}$ DeaneDrummond melihat apa yang dilakukan Nash kurang memperhatikan hukum-hukum penafsiran Alkitab. Menurutnya, Nash memaksakan teks Alkitab secara literal dalam merespons masalah biodiversitas. ${ }^{3}$

Melalui diskusi seperti itu, kita dapat melihat bahwa dalam beberapa tahun terakhir, secara umum pembicaraan teologis mengenai biodiversitas terbatas pada diskusi penafsiran Alkitab dan metodenya. Penelitian dan diskusi seperti yang dilakukan Nash, Childs, Jr., dan DeaneDrummond adalah sesuatu yang baik, tetapi bagaimanapun juga belum cukup untuk menjawab pertanyaan-pertanyaan di awal tadi, terutama ketika permasalahan biodiversitas dihubungkan dengan konteks spesifik misalnya konteks Indonesia.

Banyak orang membicarakan dan memuji keberhasilan pemerintah Indonesia dalam pembangunan infrastruktur beberapa tahun terakhir, tetapi sedikit yang peduli akan dampak buruk pembangunan tersebut terhadap laju kepunahan biodiversitas. Pembangunan yang tidak ditempatkan pada perbincangan dengan keberlanjutan ekologis,

2. James M. Childs, Jr., "The Ecology of Moral Authority: A Response to James A. Nash, 'The Bible vs. Biodiversity: The Case against Moral Arguments from Scripture'," Journal for the Study of Religion, Nature and Culture 3, no. 2 (Juni 2009): 254-59, diakses 26 September 2020, http://search.ebscohost.com/login .aspx?direct=true \&db=a6h\&AN=ATLA0001741340\&site=ehost-live.

3. Celia Deane-Drummond, "Response to James A. Nash: 'The Bible vs. Biodiversity: The Case against Moral Argument from Scripture'," Journal for the Study of Religion, Nature and Culture 3, no. 2 (Juni 2009): 271-78, diakses 26 September 2021, http://search.ebscohost.com/login.aspx?direct=true\&db=a6h \&AN=ATLA0001741362\&site=ehost-live. 
keberlanjutan biodiversitas, dan masyarakat yang bergantung penuh pada alam, ternyata hanya meninggalkan bekas dan jejak destruksi ekologis yang berdampak sosial dan ekonomis bagi ketahanan hidup masyarakat. ${ }^{4}$ Dengan kata lain, di Indonesia, laju kepunahan biodiversitas seolah-olah kurang diperhatikan. Kepedulian terhadapnya kurang, baik dari pihak pemerintah maupun masyarakat, bahkan tidak bisa dipungkiri, suara gereja sekali pun tentang hal ini hampir tidak terdengar.

Melihat kondisi tersebut, komunitas Kristen perlu bersuara secara lisan maupun tulisan dalam upaya memperjuangkan keberlanjutan biodiversitas lokal, nasional, bahkan global. Ada baiknya perjuangan itu tidak berhenti pada ranah penafsiran Alkitab dan metodenya saja, meskipun hal itu penting. Karena alasan tersebut, tulisan ini tidak ditujukan untuk masuk ke dalam perdebatan penafsiran Alkitab dan metodenya terkait biodiversitas, melainkan mencoba membangun sebuah landasan teologis mengenai biodiversitas dan menjadikannya sebagai petunjuk dalam upaya memperjuangkan keberlanjutan biodiversitas.

\section{METODE PENELITIAN}

Penelitian ini menggunakan metode studi literatur atau sering disebut sebagai metode studi pustaka. Di dalamnya, peneliti mengumpulkan dan memeriksa banyak teori serta informasi dari bahan kepustakaan menyangkut topik penelitian. Untuk itu, sumber yang

4. Bdk. Buce A. Ranboki, "Menemukan Teologi Leonardo Boff Dalam Ensiklik Paus Fransiskus Laudato Si'," Indonesian Journal of Theology 5, no. 1 (Juli 2017): 45, diakses 28 Oktober 2021, https://indotheologyjournal.org/index.php/ home/article/view/34. 
digunakan dituntut relevan dan dapat dipertanggungjawabkan secara akademis dalam hal validitas maupun keabsahannya sebagai sumber ilmiah terutama buku, jurnal, dan laporan penelitian yang kredibel baik luring maupun daring. ${ }^{5}$

Sumber-sumber yang dipilih dan digunakan difokuskan pada tiga hal, yakni krisis biodiversitas dan hutan sebagai rumah biodiversitas (darat), suara Alkitab mengenai biodiversitas dan relasinya dengan manusia, serta pentingnya perjuangan bagi keberlanjutan biodiversitas. Pembahasan dimulai dengan mengenal biodiversitas dan kondisinya saat ini, membangun sebuah landasan teologis mengenai biodiversitas, dan diakhiri dengan mengemukakan signifikansi perjuangan keberlanjutan biodiversitas berdasarkan butir-butir pembahasan sebelumnya.

\section{PEMBAHASAN}

\section{MENGENAL BIODIVERSITAS DAN KONDISINYA}

\section{Tentang Biodiversitas}

Kebergantungan kehidupan manusia terhadap biodiversitas yang berkualitas sangat besar. Tanpa biodiversitas, ekologi sebagai tempat di mana manusia berada rentan mengalami kerusakan yang signifikan. Sebaliknya, biodiversitas juga bergantung pada kebijakan dan aktivitas positif dari manusia. Keduanya saling terkait atau terikat satu dengan yang lain. Ikatan tersebut menunjukkan biodiversitas sangat bernilai bagi

5. Sonny Eli Zaluchu, "Metode Penelitian di dalam Manuskrip Jurnal Ilmiah Keagamaan," Jurnal Teologi Berita Hidup 3, no. 2 (Maret 2021): 255-56, diakses 23 Desember 2021, https://e-journal.sttberitahidup.ac.id/index.php/ jbh/article/view/93. 
keberlanjutan kehidupan manusia di bumi. $^{6}$ Karena itu, tidak mengherankan bahwa pertanian, perkebunan, pengelolaan hutan, dan perikanan menjadi kegiatan utama manusia dari dulu sampai saat ini dan akan berlanjut untuk seterusnya. ${ }^{7}$

Biodiversitas atau keanekaragaman hayati berasal dari kata biodiversity, merupakan singkatan dari biological diversity. Umumnya kata ini merujuk pada semua individu dan spesies yang hidup di wilayah tertentu. Dalam skala besar, wilayah yang dimaksud adalah seluruh bumi. Maka, biodiversitas dapat diartikan sebagai "kehidupan di bumi." Para ilmuwan kemudian memaknai biodiversitas secara lebih luas, bukan hanya dalam hal interaksi antara organisme, tetapi juga interaksi antara organisme dengan aspek abiotik khususnya lingkungan hidup mereka. Dengan demikian, biodiversitas dapat diartikan sebagai variasi kehidupan di bumi pada semua tingkatan, mulai dari gen hingga ke wilayah biogeografis, termasuk ekologi dan proses evolusi yang menopangnya. ${ }^{8}$

Selain itu, biodiversitas juga merupakan kombinasi ragam organisme dan interaksi dengan lingkungan hidupnya yang kemudian melahirkan serta menopang kehidupan di planet bumi. Oleh sebab itu,

6. Bdk. Novriana Gloria Hutagalung, "Holy Grandeur Enough for All," GEMA TEOLOGIKA: Jurnal Teologi Kontekstual dan Filsafat Keilahian 2, no. 2 (Oktober 2017): 196, diakses 25 Oktober 2021, http://journal-theo.ukdw.ac.id/ index.php/gemateologika/article/view/317.

7. Thomas E. Lovejoy, "Biodiversity: An inordinate fondness for living things," dalam Routledge Handbook of Religion and Ecology, ed. Willis Jenkins, Mary Evelyn Tucker, dan John Grim, ed. ke-1 (New York: Routledge, 2018), 250.

8. Bagian ini disarikan dari Niles Eldredge, ed., Life on Earth: An Encyclopedia of Biodiversity, Ecology, and Evolution, Vol. 1, A-G (Santa Barbara: ABC-CLIO, 2002), 1-2. 
istilah biodiversitas sangat erat dengan istilah konservasi biologis atau upaya menjaga kelestarian kehidupan semua makhluk hidup di planet bumi. Tujuannya adalah mempertahankan kekayaan spesies dan habitatnya, karena semakin manusia mampu melestarikan suatu spesies maka akan terbuka lebar keberhasilan dalam upaya pelestarian spesies yang lain. ${ }^{9}$ Upaya pelestarian tersebut tidak bisa lepas dari peran pemerintah lokal, nasional, maupun internasional. ${ }^{10}$

Secara historis, sejak pemerintahan Hindia Belanda tahun 1714, di Indonesia sudah ada inisiatif untuk melindungi kawasan hutan, misalnya hutan seluas 6 hektar di Depok sebagai cagar alam (natuur reservaat), dengan nama Cagar Alam Pancoran Mas. Namun, sampai tahun 1916 tetap terjadi perusakan cagar alam melalui maraknya perdagangan satwa dan perusakan hutan. ${ }^{11}$ Setelah itu, Indonesia juga terlibat dalam Konvensi Biodiversitas Internasional, yakni United Nations Convention on Biological Diversity (UN CBD) sejak 14 Juni 1992. UN CBD diselenggarakan di Rio de Janeiro, Brasil, dari tanggal 3-14 Juni 1992 dan menjadi awal lahirnya Deklarasi Rio, Agenda 21, yakni Konvensi tentang Perubahan Iklim dan Konvensi Biodiversitas, serta Pernyataan Prinsipprinsip Kehutanan. Konvensi-konvensi tersebut mendorong dunia global untuk menentukan kebijakan konservasi internasional seperti Taman Nasional, Kawasan Lindung se-Dunia, dan Kehutanan se-Dunia. ${ }^{12}$

9. James Maclaurin \& Kim Sterelny, What Is Biodiversity? ed. ke-1 (Chicago: University of Chicago Press, 2008), 1-4.

10. Maclaurin dan Sterelny, What Is Biodiversity? 3.

11. Jatna Supriatna, Konservasi Biodiversitas: Teori dan Praktik di Indonesia (Jakarta: Yayasan Pustaka Obor Indonesia, 2018), 2.

12. Supriatna, Konservasi Biodiversitas, 2-3. 
Sejarah tersebut menunjukkan sudah sejak lama Indonesia dan negara-negara di dunia berupaya melakukan konservasi hutan dan biodiversitas global. Namun, kenyataannya hutan dunia semakin rusak dan biodiversitasnya terancam punah. Hal ini mengancam keberlanjutan masa depan kehidupan manusia dan alam. Mimpi kemanusiaan untuk kesejahteraan bersama pun semakin sulit terealisasi jika pembiaran kerusakan hutan dan kepunahan biodiversitas terus dilakukan.

\section{Keberlanjutan Biodiversitas yang Kritis dan Hutan}

Selain laut, hutan adalah elemen yang signifikan bagi siklus kehidupan mahkluk hidup di planet bumi khususnya bagi siklus kehidupan flora dan fauna. Hutan menjadi tempat tinggal dan berkembang biak keduanya. Ketika terjadi kerusakan karena berbagai faktor atau hilangnya lahan hutan akibat proses alih lahan besar-besaran menjadi perkebunan, misalnya kelapa sawit, maka siklus kehidupan flora dan fauna pun terancam rusak bahkan punah. Hal tersebut berdampak negatif bagi kehidupan manusia mengingat manusia sangat bergantung pada keduanya sebagai komponen penting dalam pemenuhan seluruh kebutuhan pokok maupun pelengkap.

Hutan Indonesia merupakan salah satu dari tiga wilayah hutan yang mampu menjaga keseimbangan iklim global, selain hutan Amazon di Amerika Latin dan di Kongo (Afrika), karena itu disebut sebagai paru-paru dunia yang keberadaannya sangat signifikan bagi kehidupan seluruh 
dunia. ${ }^{13}$ Sekitar satu dekade yang lalu, Heather Rogers pernah mendeskripsikan sebuah skenario mengenai kerusakan hutan Indonesia akibat alih lahan besar-besaran untuk kepentingan ekonomi. Rogers mengatakan:

Imagine millions of acres of dense rain forest teeming with the world's most diverse flora and fauna. A crew armed with chain saws and bulldozers forges a narrow path through the trees. The workers begin to rip away and flatten the forest, as wildlife, including endangered species such as orangutans, flee for their lives. A bulldozer shoves innumerable splintered trees into tangled piles that stretch for miles, and crews set them alight. Ferocious fires blast through what was once a dynamic web of life, leaving behind a carbon dioxide-filled haze and a silent, charred wasteland. After the forest has been erased it's almost impossible to imagine what was done there. ${ }^{14}$

Alih lahan besar-besaran ini dilakukan untuk membuka jalan bagi perkebunan kelapa sawit, dengan alasan memenuhi kebutuhan penggunaan minyak nabati dalam berbagai macam olahan makanan, maupun untuk memproduksi biofuel, yakni bahan bakar yang diduga ramah lingkungan dan diharapkan dapat mengurangi tingkat emisi $\mathrm{CO}_{2}$. Salah satu cara yang biasa dilakukan adalah dengan membakar hutan. Kenyataannya, pembakaran hutan justru melepaskan $\mathrm{CO}_{2}$ dalam jumlah yang sangat besar, dan kemampuan perkebunan kelapa sawit itu sendiri

13. Subdirektorat Statistik Lingkungan Hidup, ed., Statistik Lingkungan Hidup Indonesia 2019 (Jakarta: Badan Pusat Statistik/BPS-Statistics Indonesia, 2019), 31.

14. Heather Rogers, Green Gone Wrong: How Our Economy Is Undermining the Environmental Revolution (London: Verso, 2010), 2. 
sangat minim dalam menyerap $\mathrm{CO}_{2}$ dibanding dengan kemampuan hutan hujan yang dirusak tersebut. ${ }^{15}$

Menurut data Badan Pusat Statistik (BPS), dari tahun 2011-2018 terjadi penurunan signifikan luas lahan hutan Indonesia dari 98,7 juta ha menjadi 93,52 juta ha. Artinya, hutan di Indonesia mengalami penurunan sebesar 0,5-1 juta ha setiap tahunnya. ${ }^{16}$ Penurunan ini diakibatkan alih fungsi hutan, pembalakan liar dan pertambangan tanpa diikuti upaya pemeliharaan atau pelestarian yang berkelanjutan. ${ }^{17} \mathrm{Hal}$ ini mengancam keberlanjutan biodiversitas yang ada di hutan Indonesia.

Mengacu pada Indonesian Biodiversity Strategy and Action Plan (IBSAP) 2015-2020 (Kementrian Perencanaan Pembangunan Nasional/Badan Perencanaan Pembangunan Nasional-KemenPPN/ BAPPENAS, 2016), BPS mencatat mengenai biodiversitas yang ada di Indonesia sebagai berikut:

Keanekaragaman hayati Indonesia yang terdiri dari 1.605 jenis burung, 723 jenis reptil, 385 jenis amphibi, 720 jenis mamalia, 1.248 jenis ikan air tawar, 197.964 jenis invertebrata, 5.137 jenis arthropoda (termasuk jenis-jenis arachnida), serta 181.847 jenis serangga termasuk 30.000 diantaranya dari ordo hymenoptera (tawon, lebah dan semut). Sedangkan dalam dunia flora, keanekaragamannya terdiri dari 91.251 jenis tumbuhan berspora, 120 jenis gymnospermae, serta sekitar 30.000-40.000

15. Daniel Murdiyarso, et al., "Meninjau Kembali Kebijakan Alih-Guna Lahan dan Keberkelanjutan Sektor Sawit di Indonesia," Akademi IImu Pengetahuan Indonesia, no. 1 (2020): 1.

16. Lih. "Badan Pusat Statistik," diakses 19 Oktober 2021, https://www.bps.go.id/publication.html?Publikasi\%5BtahunJudul\%5D=\&Publika si\%5BkataKunci\%5D=hutan\&Publikasi\%5BcekJudul\%5D=0\&yt0=Tampilkan .

17. Statistik Lingkungan Hidup Indonesia 2019, 33. 
jenis tumbuhan berbunga (angiospermae), yang hingga saat ini baru teridentifikasi 19.112 jenis (Kementerian Lingkungan Hidup dan Kehutanan, Republik Indonesia-KLHK, 2018). Banyak spesies itu bersifat endemik, yaitu hanya dapat dijumpai di Indonesia. ${ }^{18}$

Kerusakan atau hilangnya hutan akibat deforestasi dan alih lahan berbanding lurus dengan kepunahan biodiversitas di Indonesia. Akibat langsung dari hal ini yang berdampak global dan lokal adalah peningkatan gas rumah kaca, penurunan signifikan biodiversitas, bahkan penghilangan akses penduduk lokal atas lahan yang telah menjadi hak turun temurun mereka dalam melangsungkan kehidupan. ${ }^{19}$ Sebagai gambaran, emisi karbon yang dihasilkan akibat kehilangan hutan, terutama hutan primer, adalah $2.64 \mathrm{Gt} \mathrm{CO}_{2}$ yang setara dengan emisi tahunan yang dihasilkan oleh 570 juta mobil, lebih dari dua kali lipat jumlah mobil di jalan raya negara sebesar Amerika Serikat. ${ }^{20}$

Bukan hanya Indonesia, beberapa negara penghasil hutan primer di tahun 2020 juga mengalami kehilangan hutan primer yang sangat banyak. Berikut gambarannya:

18. Statistik Lingkungan Hidup Indonesia 2019, 31.

19. Murdiyarso, et al., "Meninjau Kembali Kebijakan Alih-Guna Lahan dan Keberkelanjutan Sektor Sawit di Indonesia," 1.

20. Mikaela Weisse dan Elizabeth Goldman, "Kerusakan Hutan Hujan Primer Meningkat Sebesar 12\% Dari Tahun 2019 Hingga Tahun 2020 | WRI Indonesia," last modified 1 April 2021, diakses 19 Oktober 2021, https://wriindonesia.org/id/blog/kerusakan-hutan-hujan-primer-meningkat-sebesar-12dari-tahun-2019-hingga-tahun-2020. 


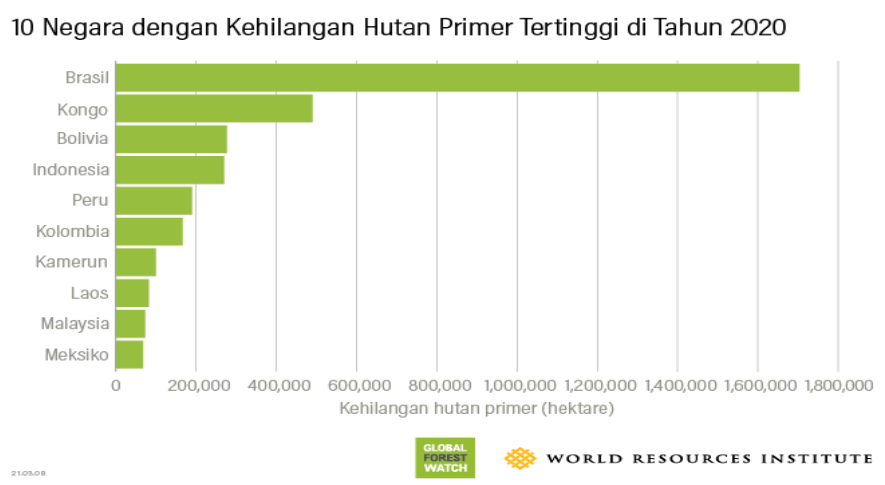

Gambar 1. 10 Negara dengan Kehilangan Hutan Primer Tertinggi Tahun 2020. ${ }^{21}$

Kehilangan hutan primer yang dialami 10 negara tersebut sangat mengancam biodiversitas bumi. Di Indonesia misalnya, deforestasi yang didorong oleh produksi komoditas menjadi penyebab utama kehilangan hutan. Hal itu juga terjadi di Amerika Latin dan negara lain di Asia Tenggara. Sementara itu, alih lahan hutan, kebakaran, dan dampak terkait iklim global terus berperan signifikan baik di wilayah tropis maupun di sekitarnya. ${ }^{22}$ Di Indonesia, diketahui setiap lima tahun terjadi peningkatan alih lahan hutan menjadi perkebunan kelapa sawit. Misalnya, dari tahun 2010-2015 diperkirakan terjadi peningkatan alih lahan dari 16 juta ha menjadi hampir 26 juta ha. ${ }^{23}$ Cara yang diduga baik, yaitu memaksimalkan

21. “Apa Yang Terjadi Pada Hutan Global Pada 2020? | Global Forest Watch Blog," Global Forest Watch Content, last modified 31 Maret, 2021, diakses 19 Oktober 2021, https://www.globalforestwatch.org/blog/id/data-andresearch/data-kehilangan-tutupan-pohon-global-2020.

22. Bdk. Weisse dan Goldman, "Kerusakan Hutan Hujan Primer Meningkat Sebesar 12\% Dari Tahun 2019 Hingga Tahun 2020 | WRI Indonesia."

23. Rogers, Green Gone Wrong: How Our Economy Is Undermining the Environmental Revolution, 99-100. 
biofuel melalui kelapa sawit, justru menjadi cara terbaik dalam mendukung kepunahan biodiversitas, bahkan tidak mengurangi peningkatan $\mathrm{CO}_{2}$ sama sekali. ${ }^{24}$

Di Eropa, masalah lain muncul. Langkah-langkah penghijauan terbaru justru dikritik oleh banyak ahli ekologi dan berbagai organisasi lingkungan karena menetapkan persyaratan yang terlalu rendah untuk menghentikan laju kehilangan biodiversitas. ${ }^{25}$ Mayoritas pemerintah Eropa tidak memilih langkah-langkah yang efektif untuk melestarikan biodiversitas. Bahkan langkah-langkah penghijauan yang diambil terkendala masalah beban administrasi bagi petani dengan pihak berwenang. ${ }^{26}$ Dengan perkataan lain, penghijauan terbaru bermasalah di dalam desain dan implementasinya yang berdampak negatif bukan hanya pada keberlanjutan biodiversitas, tetapi juga dalam hal tindakan praktis partisipasi petani dalam upaya penghijauan.

Penting untuk diingat bahwa biodiversitas termasuk dalam ekosistem, komunitas kehidupan yang mestinya seimbang. Sedangkan, hutan adalah rumah bagi biodiversitas darat dan bagian integral dari ekosistem. Jika pelestarian ekosistem harus menjadi prioritas, perhatian pada keberlanjutan biodiversitas harus ditingkatkan karena pada dasarnya biodiversitas memiliki nilai yang mahal bagi kehidupan manusia.

24. Richard Bauckham, Living with Other Creatures: Green Exegesis and Theology (Waco: Baylor University Press, 2011), 214.

25. Guy Pe'er, et al., "Adding Some Green to the Greening: Improving the EU's Ecological Focus Areas for Biodiversity and Farmers," Conservation Letters 10, no. 5 (2017): 517-30, diakses 22 Oktober 2021, https://onlinelibrary.wiley. com/doi/abs/10.1111/conl.12333.

26. Pe'er, et al., “Adding Some Green to the Greening," 517-30. 
Sementara itu, jika biodiversitas dijadikan prioritas, perhatian bagi per spesies harus ditingkatkan. ${ }^{27}$ Sebagai bagian dari komunitas global, komunitas Kristen atau gereja perlu untuk memperjuangkan hal ini, yang dapat dimulai dengan melihat landasan teologis mengenai biodiversitas.

\section{LANDASAN TEOLOGIS TENTANG BIODIVERSITAS}

Upaya memperjuangkan keberlanjutan biodiversitas membutuhkan landasan teologis yang baik dan benar. Setidaknya ada tiga hal yang dapat dijadikan landasan. Pertama, melihat kembali apa yang dikatakan Alkitab mengenai biodiversitas. Kedua, melihat relasi biodiversitas dan manusia di dalam Alkitab. Hal ini penting sebab kebijakan-kebijakan manusia berimplikasi signifikan pada keberlanjutan biodiversitas. Ketiga, pemahaman bahwa biodiversitas hanya sekadar komoditi yang terus dieksploitasi dengan alasan pemenuhan kebutuhan pokok atau kepentingan ekonomi perlu diubah. Dalam Kekristenan, biodiversitas memiliki tempatnya sendiri. Iman Kristen meyakini selain melalui Kristus dan Alkitab, Allah juga menyatakan diri dan berkarya melalui ciptaan. Dengan kata lain, Allah menyatakan diri dan kehendakNya melalui biodiversitas.

\section{Biodiversitas dalam Alkitab}

Perjanjian Lama menyadari keberadaan biodiversitas. Di dalam kisah penciptaan (Kej. 1), keberadaan biodiversitas dikemukakan dengan jelas. Ada frasa kunci yang akan sering kita temukan dan dengarkan di

27. Bauckham, Living with Other Creatures, 217. 
dalamnya, yakni "dari setiap jenis" atau "menurut jenisnya." Kita dapat mendengar dan melihat mengenai buah-buahan dari berbagai jenis pohon, tumbuhan berbiji dari segala jenis, segala jenis makhluk laut, segala jenis burung, segala jenis binatang liar, segala jenis binatang piaraan, segala jenis binatang melata, yakni reptil dan serangga. Kemunculan bagian ini kurang lebih sebanyak sepuluh kali, khususnya di hari ketiga, kelima, dan keenam penciptaan (Kej. 1:11, 12, 21, 24, 25). ${ }^{28}$

Hal di atas melukiskan dunia yang penuh dengan "banyak," bentuk kehidupan yang berbeda-beda. Holmes Rolston meyakini bahwa spesies atau biodiversitas sejak mula adalah kehendak Allah sendiri yang memang menginginkan bumi ini memiliki biodiversitas. ${ }^{29}$ Pada hari kelima dan keenam Alkitab menyatakan bahwa Allah memberkati mereka (Kej. $1: 22$, 28). la memberkati biodiversitas yang diciptakan-Nya. Allah memberikan karunia kesuburan bagi biodiversitas sebab Dia memampukan semua mahkluk untuk "berbuah dan berkembang biak." ${ }^{30}$ Dengan demikian, kehendak Sang Pencipta bukan hanya memberikan berkat keberadaan biodiversitas, tetapi juga memberikan kelimpahan baginya.

Richard Bauckham menilai semua terjemahan bahasa Inggris dari Kejadian 1 sepertinya menggunakan kata jenis (mahkluk dari segala jenis atau menurut jenisnya), tetapi terjemahan dari kata Ibrani (min)

28. Bauckham, Living with Other Creatures, 218.

29. Holmes Rolston, "Environment," dalam The Routledge Companion to Theism, ed. Charles Taliaferro, Victoria S. Harrison, dan Stewart Goetz, ed. ke-1 (New York: Routledge, 2012), 545.

30. Bauckham, Living with Other Creatures, 218. 
mengarah atau dapat diartikan sebagai spesies. Menurutnya, kata ini memang hanya digunakan untuk jenis tumbuhan atau hewan, bukan untuk jenis hal yang lain. ${ }^{31}$

Kisah air bah menyinggung tentang berkat keberadaan dan kelimpahan bagi biodiversitas. Kasih Allah terhadap biodiversitas terlihat jelas sebelum air bah terjadi. Dalam Kejadian 6:19, Allah sendiri yang memerintahkan Nuh untuk mengambil satu pasang dari semua yang hidup, dari segala mahkluk, dan dibawa masuk ke dalam bahtera agar terpelihara hidupnya bersama keluarga Nuh baik pada saat air bah maupun setelahnya. Hal itu adalah bukti perjanjian yang bersifat ekumenis dan ekologis, serta menunjukkan bahwa semua jenis hewan adalah milik Allah (bdk. Mzm. 50:10-11). ${ }^{32}$ Bauckham mengatakan bahwa meskipun saat itu penulis Yahudi tidak terlalu memahami mengenai spesies sama seperti pemahaman kita saat ini, tetapi tetap dicatat bagaimana Nuh memilih hewan secara berpasangan, sesuai jenisnya, baik jantan maupun betina dengan tujuan agar hewan-hewan tersebut dapat berkembang biak setelah air bah surut, sesuai pemeliharaan dan berkat Allah yang nantinya terealisasi dalam kisah selanjutnya. ${ }^{33}$

Biodiversitas sebagai ciptaan Allah memiliki de-divinized, tetapi bukan de-sakralisasi alam. Biodiversitas tetap suci dalam arti bahwa itu milik Allah, ada untuk kemuliaan Allah, bahkan mencerminkan kemuliaanNya seperti yang seharusnya dilakukan manusia sebagai gambar Allah. ${ }^{34}$

31. Bauckham, Living with Other Creatures, 218.

32. Rolston, "Environment," 546.

33. Bauckham, Living with Other Creatures, 218.

34. Bdk. Bauckham, Living with Other Creatures, 13. 
Pengakuan akan kapasitas biodiversitas sebagai ciptaan yang mencerminkan kemuliaan Allah berkontribusi pada pembaruan minat mendekati biodiversitas sebagai bagian wahyu Allah Tritunggal (wahyu umum). Hal ini dapat membangun refleksi teologis pada teks-teks seperti Mazmur 19:1 dan Roma 1:20. Misalnya, perkataan Basil dari Kaisarea yang dikutip J.J. Johnson Leese demikian, "I want creation to awaken such a profound admiration in you, that in every place, whatever plants you may contemplate, you are overcome by a living remembrance of the Creator." ${ }^{35}$ Demikian juga dengan teks-teks lain seperti Ayub 12:7-9, Amsal 6:6-9. Apalagi teks Perjanjian Baru seperti Yohanes 1:1-3 dan Kolose 1:15-20 yang mengarahkan manusia pada Allah ketika berinteraksi dengan berbagai jenis ciptaan (biodiversitas). ${ }^{36}$

\section{Biodiversitas dan Manusia dalam Alkitab}

Keberadaan biodiversitas sangat signifikan bagi kehidupan manusia. Contoh terkecil adalah manusia membutuhkan berbagai spesies tanaman untuk dijadikan sebagai obat-obatan. Alkitab sendiri setidaknya menyebutkan secara langsung lima spesies tanaman yang dapat dijadikan sebagai obat, yakni Ara, Nard, Hisop, balsam Gilead, dan Mandraka. Seperti yang diungkapkan Amots Dafni dan Barbara Bock dalam hasil penelitian mereka:

35. J.J. Johnson Leese, "Ecofaith: Reading Scripture in an Era of Ecological Crisis," Religions 10, no. 3 (Maret 2019): 7, diakses 22 Oktober 2021, https://www.mdpi.com/2077-1444/10/3/154.

36. Leese, "Ecofaith," 7. 
In our survey, we suggest reducing this list to 45 plant species. Our contribution comprises 20 "newly" suggested Biblical Medicinal Plants. Only five species are mentioned directly as medicinal plants in the Bible: Fig (Ficus carica), Nard (Nardostachys jatamansi), Hyssop (Origanum syriacum), balm of Gilead (Commiphora gileadensis) and Mandrake (Mandragora officinarum). No fewer than 18 medicinal plants are mentioned in old Jewish post-Biblical sources, in addition to those in the Bible. Most of these plants (15) are known also in Egypt and Mesopotamia while three are from Egypt only. Seven of our suggested species are not mentioned in the Bible or in the Jewish post-Biblical literature but were recorded as medicinal plants from Egypt, as well as from Mesopotamia. It is quite logical to assume that they can be included as Biblical Medicinal Plants. ${ }^{37}$

Alkitab mencatat adanya penggunaan tumbuhan untuk pengobatan, misalnya penggunaan balsam untuk mengobati luka (Yer. $8: 22 ; 46: 11 ; 51: 8)$ dan bagaimana raja Hizkia diobati dengan ara (2Raj. $20: 7) .^{38}$

Biodiversitas telah lama berkontribusi bagi pengobatan manusia. Misalnya, aspirin adalah obat terlaris sepanjang masa, yang awalnya diresepkan sebagai analgesik di Yunani Kuno ketika disiapkan sebagai infus, dan digunakan pada saat Perang Dunia ke-2. ${ }^{39}$ Thomas E. Lovejoy

37. Amots Dafni dan Barbara Böck, "Medicinal Plants of the BibleRevisited," Journal of Ethnobiology and Ethnomedicine 15, no. 1 (November 2019): 1, diakses 22 Oktober 2021, https://doi.org/10.1186/s13002-019-0338-8.

38. Dafni dan Böck, "Medicinal Plants of the Bible-Revisited," 2.

39. Analgesik adalah obat untuk meredakan rasa nyeri tanpa mengakibatkan hilangnya kesadaran. Lih. "Arti Kata Analgesik - Kamus Besar Bahasa Indonesia (KBBI) Online," diakses 29 Oktober 2021, https://kbbi.web.id/ analgesik. 
mengatakan biodiversitas adalah peti atau perpustakaan yang luar biasa bagi kedokteran dan ilmu biologis lainnya. ${ }^{40}$

Upaya melihat signifikansi biodiversitas terhadap kehidupan manusia dapat dimulai dengan membaca kembali relasi manusia dengan biodiversitas sebagai ciptaan di dalam Alkitab melalui kacamata ekoteologis. ${ }^{41}$ Relasi dominatif, otoritatif, atau eksploitatif yang biasanya dikenal sebagai realitas dualisme hierarkis, perlu untuk diklarifikasi. Klarifikasi istilah Ibrani (radah atau kabash) yang seringkali diterjemahkan sebagai "to rule" dan "to have dominion" menjadi signifikan di sini. ${ }^{42}$ Ellen Davis memberikan alternatif pemahaman istilah tersebut. Menurutnya, untuk menghindari nada eksploitatif, kisah penciptaan perlu dibaca dalam model puisi. Manusia adalah imam ciptaan yang diberikan amanat untuk "berbuah dan berkembang biak, memenuhi bumi dan menaklukkannya, serta memiliki kuasa atas ciptaan lain (Kej. 1:28)." Hal itu merupakan sebuah petunjuk bagi manusia bukan untuk mengeksploitasi, melainkan untuk melatih cara menguasai yang terampil dalam konteks yang lebih luas dari berkat yang Allah berikan bagi hewan (Kej. 1:22) maupun tanah yang disediakan Allah, Pencipta dan Pengasih (Kej. 1:29-30), bagi seluruh ciptaan. $^{43}$

Pemahaman di atas dapat berfungsi sebagai pembentuk peran yang unik dari kemanusiaan sekaligus penegasan akan keanggotaan

40. Lovejoy, "Biodiversity," 250.

41. Leese, "Ecofaith," 6.

42. Leese, "Ecofaith," 6-7.

43. Ellen F. Davis, Scripture, Culture, and Agriculture: An Agrarian Reading of the Bible, edisi ke-1. (Cambridge: Cambridge University Press, 2008), 53-60. 
komunal manusia bersama semua mahkluk hidup, semua biodiversitas. ${ }^{44}$ Sementara itu, pemahaman itu juga dapat menolong manusia untuk terhindar dari sifat struktur antroposentris dan lebih mengarah pada struktur ekosentris dan teosentris, di mana subjek utamanya adalah bumi, ciptaan (biodiversitas), lalu fungsi manusia sebagai co-creatornya Allah. ${ }^{45}$

Tujuh pengulangan frasa "dan Allah melihat bahwa (semuanya) itu baik (tob)" (Kej. 1:4, 10, 12, 18, 21, 25, 31) adalah penegasan tentang integritas, nilai, dan keindahan ciptaan, keindahan biodiversitas yang benar-benar terpisah dari kemanusiaan. Sebagai co-creator Allah, hal ini menjadi perhatian utama manusia dalam memupuk kesadaran ekosentris dan teosentris. ${ }^{46}$ Ketika narasi penciptaan pertama ditempatkan berdampingan dengan narasi penciptaan kedua (Kej. 2:4b-3:24), tematema tentang bumi, ciptaan (biodiversitas), dan fungsi co-creator semakin menonjol. ${ }^{47}$ Adam, hewan dan burung, maupun tanaman memiliki sumber keberadaannya dari bumi/tanah (Kej. 2:7, 19). Adam, bumi/tanah, hewan, tumbuhan, semua biodiversitas disorot dalam hubungan kekerabatan yang kental. Hal ini menegaskan kuatnya keterkaitan yang dimiliki manusia dengan organisme dan ekosistem, sejak awal manusia terkait dengan biodiversitas. ${ }^{48}$

44. Bdk. Paul Copan, "Bioethics," dalam The Routledge Companion to Theism, ed. Charles Taliaferro, Victoria S. Harrison, dan Stewart Goetz, ed. ke-1 (New York: Routledge, 2012), 522-23.

45. Bdk. Davis, Scripture, Culture, and Agriculture, 53-65.

46. Leese, "Ecofaith," 6.

47. Rolston, "Environment," 543-45.

48. Bdk. Leese, "Ecofaith," 6. 
Realitas dualisme hierarkis antara manusia dan biodiversitas tidak lagi dapat dipertahankan. Realitas tersebut harus diruntuhkan atau didekonstruksi. Sejak awal, manusia dan biodiversitas memiliki hubungan timbal balik yang dinamis. Manusia dan biodiversitas dirancang untuk hidup berdampingan dalam bumi bukan dalam dualisme hierarkis. Manusia hanyalah salah satu spesies dalam ekosistem bumi, mereka harus berbagi bumi sebagai rumah dengan semua organisme hidup lainnya, dan sepenuhnya bergantung pada kesehatan ekosistem yang berkelanjutan untuk kelangsungan hidup mereka sendiri.

Ernst M. Conradie sudah lama menekankan mengenai bumi sebagai rumah semua makhluk hidup. Ekologi bumi secara etimologis berasal dari istilah Yunani oikos, yang berarti "rumah" atau rumah tangga, terkait dengan istilah oikonomia, dipahami sebagai "pengurusan" atau "manajemen." ${ }^{49}$ Secara teologis, istilah tersebut menggambarkan pekerjaan Allah Tritunggal yang meliputi semua ciptaan (misalnya Ef. 1:10), dengan orang Kristen sebagai anggota dari rumah tangga Allah (Ef. 2:19-22). Istilah alkitabiah seperti bumi (ge), alam (physis), dan penciptaan (ktisis) merujuk pada elemen-elemen ciptaan yang berbeda, tergantung

49. Lih. Ernst M. Conradie, "The Whole Household of God (Oikos): Some Ecclesiological Perspectives: Part 1," Scriptura: Journal for Biblical, Theological and Contextual Hermeneutics 94 (2007): 1-9, diakses 22 Oktober 2021, https://scriptura.journals.ac.za/pub/article/view/1431. Lih. juga Ernst M. Conradie, "The Whole Household of God (Oikos): Some Ecclesiological Perspectives (Part 2)," Scriptura: Journal for Biblical, Theological and Contextual Hermeneutics 94 (2007): 10-28, diakses 22 Oktober 2021, https://scriptura .journals.ac.za/pub/article/view/1436. 
pada konteks yang lebih luas. Meskipun begitu, istilah tersebut mencakup semua makhluk hidup termasuk manusia. ${ }^{50}$

Keterkaitan segala sesuatu di dalam bumi, khususnya biodiversitas dan manusia, tidak bisa dihindari. Salah satu petunjuk mengenai hal itu adalah adanya sifat sakramental biodiversitas yang menjadi sarana relasi pencipta dengan ciptaan-Nya atau sebaliknya.

\section{Sifat Sakramental Biodiversitas}

Apa yang bisa kita pelajari tentang Allah melalui ciptaan-Nya? Mengapa dalam kisah penciptaan dan juga narasi Alkitab selanjutnya, tampak seolah-olah Allah punya minat yang besar terhadap berbagai jenis hewan dan tumbuhan selain manusia? Pertanyaan-pertanyaan ini dapat menjadi kompas cara pandang kita terhadap sifat sakramental biodiversitas.

Sebagai awalan, Kevin J. O'Brien pernah mengatakan suatu hal yang menarik. Menurutnya, jika kita bisa mengerti Allah dengan memahami ciptaan-Nya, kita juga harus berusaha untuk memahami berbagai kehidupan (biodiversitas) di dalam ciptaan itu. Dengan kata lain, jika kita ingin mengerti peran kita di dunia ini, kita harus memahami keterkaitan mendasar kita dengan biodiversitas dan kepunahan. ${ }^{51}$ Salah satu keterkaitan tersebut ada dalam sifat sakramental biodiversitas.

Sakramen secara sederhana dapat dipahami sebagai praktik ritual yang membangun hubungan antara dunia dan Allah. Contohnya

50. Leese, "Ecofaith," 6.

51. Kevin J. O'Brien, An Ethics of Biodiversity: Christianity, Ecology, and the Variety of Life (Washington: Georgetown University Press, 2010), 58-59. 
adalah tentang Perjamuan Kudus, melalui cara yang benar dan disetujui bersama (Mat. 26:26-27). Melalui roti dan anggur diyakini ada persekutuan erat antara orang percaya dengan Allah dalam proses Perjamuan Kudus.

Sakramen memiliki dua sisi. Di satu sisi, sakramen itu nyata, nyata dalam hal-hal material yang menghubungkan langsung komunitas Kristen dengan Sang Pencipta. Di sisi lain, sakramen itu misteri yang menunjukkan batas kemampuan kita untuk sepenuhnya memahami Allah dan karyaNya di dunia ini. Sakramen menghubungkan kita dengan misteri llahi. ${ }^{52}$

Sifat sakramental dapat ditarik ke dalam pembicaraan mengenai biodiversitas. Jika Allah dapat dikomunikasikan dan dialami melalui materi tertentu, masuk akal untuk klaim lanjutan bahwa Allah hadir dalam elemen dasar, atau Allah ada melalui cara-Nya sendiri dalam semua gandum, anggur, hidrogen, oksigen, dan semua bentuk ciptaan di seluruh dunia. Makna "melalui cara-Nya sendiri" menunjukkan pemahaman ini berbeda dengan paham panteisme atau panenteisme. Maksudnya adalah semua ciptaan menandakan bahwa Allah ada bukan hanya secara transenden, melainkan juga secara imanen (material), berkarya secara langsung dan berkelanjutan melalui keberadaan ciptaan. Salah satu contohnya ada dalam kejadian inkarnasi Yesus Kristus di bumi yang menandakan suatu hubungan berkelanjutan antara pencipta dan ciptaan..$^{53}$ Allah memilih untuk datang ke dunia dan berkarya dalam materi (badan/tubuh).

52. O'Brien, An Ethics of Biodiversity, 59.

53. O'Brien, An Ethics of Biodiversity, 59-60. 
Allah dapat dikenal melalui dunia ciptaan-Nya karena dunia mengomunikasikan tentang-Nya. Alkitab juga menyatakan bahwa Sang Pencipta itu aktif hadir di dalam atau melalui ciptaan-Nya. Injil Yohanes mengatakan dengan jelas tentang hal ini, bahwa Allah "berada di dunia, dan dunia menjadi ada melalui-Nya," di mana Kristus, yang adalah inkarnasi Allah, datang "ke rumah-Nya sendiri" (Yoh. 1:2-3, 10-11).

Implikasi ekologis dari paham sakramentalis semacam itu adalah jika iman Kristen mengajarkan bahwa dunia mengungkapkan Allah, jelas orang Kristen harus berhati-hati dan antisipatif terhadap dampak manusia pada bumi, bahwa kita harus mempraktikkan sistem yang benar dan hormat terhadap alam di sekitar kita. ${ }^{54} \mathrm{Hal}$ itu dapat dikaitkan dengan ide de-divinized biodiversitas seperti yang dikemukakan Bauckham. Maksud dari de-divinized biodiversitas adalah biodiversitas tetap suci dalam artian itu milik Allah, ada untuk kemuliaan Allah, bahkan mencerminkan kemuliaan-Nya. ${ }^{55}$ Biodiversitas sebagai ciptaan Allah memiliki dedivinized, tetapi bukan desakralisasi alam. Artinya, iman Kristen tidak sedang mendesakralisasi alam. Senada dengan apa yang disampaikan Nash:

Nature is sacred by association, as the bearer of the sacred. We are standing perpetually on holy ground, because God is present not only in the burning bush but in the nurturing soil and atmosphere, indeed, sharing the joys and agonies of all creatures.

54. O'Brien, An Ethics of Biodiversity, 60.

55. Bauckham, Living with Other Creatures, 13. 
The sacramental presence of the Spirit endows all of creation with a sacred value and dignity. ${ }^{56}$

Melihat hal itu, degradasi ekologis atau laju kepunahan biodiversitas dapat dikatakan sebagai dosa, sebab melaluinya kita melupakan sifat sakramental ciptaan, dan melupakan tanggung jawab manusia dalam memelihara hasil karya kreatif Allah. Pelestarian biodiversitas diperjuangkan karena itu adalah tanda Allah ada, karya kreatif Allah, dan salah satu sarana bagi kita untuk mengenal serta mendekat pada-Nya; singkatnya, karena biodiversitas bersifat sakramental.

\section{SIGNIFIKANSI MEMPERJUANGKAN KEBERLANJUTAN BIODIVERSITAS:}

\section{ALASAN PELESTARIAN BIODIVERSITAS HARUS DILAKUKAN}

Agama atau kepercayaan seseorang terkait dengan ekologi. Seperti yang diungkapkan Roger S. Gottlieb bahwa bagaimanapun juga agama atau kepercayaan seseorang sangat terkait dengan ekologi alam. Ekologi pada dasarnya ramah dengan agama karena memiliki dimensi spiritualitas. ${ }^{57}$ Melaluinya umat beragama difasilitasi untuk memiliki hubungan spiritualitas dengan yang disebut sebagai Tuhan atau Allah. Degradasi ekologis atau laju kepunahan biodiversitas dapat dikatakan sebagai redupnya kepekaan manusia akan kehadiran Allah di alam

56. James Nash, Loving Nature: Ecological Integrity and Christian Responsibility (Nashville: Abingdon, 1991), 115.

57. Roger S. Gottlieb, "Introduction: Religion and Ecology-What Is the Connection and Why Does It Matter?" dalam The Oxford Handbook of Religion and Ecology, ed. Roger S. Gottlieb, ed. ke-1 (Oxford: Oxford University Press, 2010), 11-12. 
ciptaan-Nya. Sementara itu, iman Kristen justru meyakini keaktifan Allah dalam berelasi dengan umat-Nya dan berkarya di dalam atau melalui ciptaan.

Melalui pembahasan di bagian sebelumnya, kita dapat melihat bagaimana biodiversitas terkait dengan manusia, begitu pun sebaliknya. Bukan hanya itu, biodiversitas juga memiliki sifat sakramental. Karena itu, degradasi ekologis atau laju kepunahan biodiversitas merupakan perusakan yang berbahaya bagi kemampuan manusia untuk mengenal dan menanggapi Allah. Sifat sakramental biodiversitas bukan hanya merangsang ide abstrak keterkaitan manusia dengan Allah, juga bukan hanya sebuah ide atau klaim teologis yang sangat jauh (transenden). Pada dasarnya sifat sakramental biodiversitas merupakan sarana bagi manusia untuk mengalami Allah di bumi, karena dapat menginspirasi seseorang untuk bertindak benar dalam menjalani kehidupan mereka serta berinteraksi dengan alam dan biodiversitasnya. Setidaknya, sakramentalitas biodiversitas dapat mengubah cara orang Kristen berperilaku melalui konversi cara berpikir, merasa tentang alam serta biodiversitasnya, dan bertindak terhadapnya sesuai penyataan wahyu Allah. ${ }^{58}$

Kesadaran sakramental dapat mendorong seseorang untuk memahami bahwa degradasi ekologis dan kepunahan biodiversitas adalah dosa terhadap Allah, di saat yang sama juga dapat menipiskan kemampuannya untuk mengenal Allah. Kesadaran ini mengajarkan

58. O'Brien, An Ethics of Biodiversity, 61. 
bahwa tanggapan orang Kristen terhadap degradasi ekologis dan kepunahan biodiversitas begitu signifikan bagi orang lain. ${ }^{59}$

Peran orang Kristen sangat besar dan dibutuhkan komunitas global dalam menjalani kesadaran sakramental ini. Melaluinya, kita mendapatkan keberanian dan tekad untuk mengubah interaksi negatif dengan alam maupun biodiversitasnya yang selama ini terjadi, menjadi interaksi positif berkelanjutan yang menempatkan Allah sebagai pencipta, manusia sebagai co-creator Allah, dan biodiversitas sebagai bagian integral komunitas bumi. Namun, perubahan kesadaran ini belum cukup dan perlu ditopang oleh upaya nyata yang berdampak langsung terhadap biodiversitas berkelanjutan.

Dalam kurun waktu 10 tahun terakhir, relasi ekonomi dan ekologi sangat berpengaruh terhadap masalah biodiversitas. Salah satu teolog yang membaca kondisi ini adalah Bauckham. la menyetujui pendapat umum yang mengakui bahwa para ekonomlah yang benar-benar menjalankan dunia saat ini. Baginya, saat ini manusia terlalu ambisius dalam membuat segala sesuatu menjadi sumber uang, akibatnya jasa ekosistem dipersempit menjadi sekadar penghasil keuntungan atau komoditas ekonomi. ${ }^{60}$ Padahal hakikatnya jasa ekosistem, yang di dalamnya ada biodiversitas, tidak hanya ada untuk kepentingan ekonomi, tetapi juga untuk menopang siklus kehidupan seluruh mahkluk hidup di bumi. Sebagai contoh, satu spesies kumbang sangat berharga bagi

59. O'Brien, An Ethics of Biodiversity, 61.

60. Bauckham, Living with Other Creatures, 230. 
peternakan atau perkebunan dalam proses perkembangbiakan hewan atau tumbuhan tertentu.

Bumi membutuhkan seluruh jasa ekosistem atau jasa biodiversitas. Hutan menyerap banyak $\mathrm{CO}_{2}$ yang dihasilkan aktivitas manusia. Hutan menghilangkan polutan dari atmosfer. Sementara itu, vegetasi (dunia tumbuh-tumbuhan/pepohonan) dan biodiversitas mengurangi risiko banjir juga menghasilkan sumber air minum yang bersih. ${ }^{61} \mathrm{Hal}$ itu memiliki benang merah dengan iman Kristen tentang ciptaan. Segala sesuatu yang diciptakan Allah memiliki nilai bagi-Nya. Semua biodiversitas, semua jenis hewan dan tumbuhan, memiliki nilai intrinsik, karena semuanya diciptakan Allah, dan Allah menunjukkan apresiasi nilai intrinsik tersebut di dalam kisah penciptaan, ketika la melihat segala yang diciptakan-Nya “... sungguh amat baik" (Kej. 1:31). Hal itu adalah anugerah yang perlu dijaga oleh manusia. ${ }^{62}$

Mengenali dan menghargai nilai intrinsik biodiversitas dapat menyentak kita untuk keluar dari lingkaran egosentris yang saat ini sangat terlihat dari cara kita berbisnis, mengambil kebijakan, dan melihat keberadaan berbagai spesies hewan atau tumbuhan. Bahkan ketika kita menikmati kelucuan dari seekor panda raksasa yang memikat hati, itu pun hanya untuk memuaskan rasa kagum, memuaskan rasa kekosongan kita akan hiburan dalam padatnya aktivitas sehari-hari. Kebanyakan orang tidak memiliki kemurnian untuk melihat, memperhatikan, dan

61. Bauckham, Living with Other Creatures, 230.

62. Pope Benedict XVI, The Garden of God: Toward a Human Ecology (Washington: The Catholic University of America Press, 2014), 63. 
memperjuangkan nilai instrinsik biodiversitas. Sedangkan, sejak awal Allah justru sangat menghargai nilai instrinsik semua mahkluk-Nya dan terus memelihara serta merawatnya (Mat. 6:25-26).

Cara pandang orang Kristen terhadap biodiversitas berbeda dengan cara pandang orang lain. Jika kita membiarkan dan mempercayakan kualitas biodiversitas dikendalikan para ekonom terutama ekonom yang tidak bertanggung jawab, kita sedang membiarkan diri dibawa ke dalam ilusi egosentris yang merusak biodiversitas dan kualitas kemanusiaan. Ilusi tersebut menyesatkan dan patut disesali atau dilawan, karena hanya berpusat pada diri sendiri, kepentingan diri sendiri, yang hanya mementingkan atau mengagungkan nilai intrinsik manusia. Biodiversitas dipaksa bergantung atau berpusat pada pemikiran manusia, dan meminggirkan intuisi nyata dari nilai intrinsik biodiversitas itu sendiri. Seolah-olah biodiversitas bernilai hanya ketika kita berpikir itu bernilai. ${ }^{63}$ Kita semua, manusia maupun biodiversitas dan seluruh ciptaan Allah, memiliki nilai intrinsiknya masingmasing, di mana semuanya hanya bergantung pada Allah bukan pada pikiran manusia. ${ }^{64}$

Ada alternatif jalan yang lebih baik untuk memperjuangkan keberlanjutan biodiversitas. Kita perlu memikirkan kembali yang disebut sebagai jasa ekosistem. Bukan hanya alam yang harus melakukan banyak hal bagi manusia, tetapi manusia juga perlu memperjuangkan kesehatan alam yang berkelanjutan, karena manusia sendiri sebenarnya adalah milik

63. Bauckham, Living with Other Creatures, 232.

64. Copan, "Bioethics," 520-21. 
alam ini atau berasal dari yang alami (debu tanah). Manusia perlu menciptakan biodiversitas yang sehat dan berkelanjutan, bukan hanya untuk kepentingan manusia saja, tetapi juga untuk kepentingan biodiversitas itu sendiri. ${ }^{65}$ Kita bergantung pada siklus kehidupan atau jaringan kehidupan planet bumi yang kompleks sama seperti apa yang dialami oleh semua spesies hewan dan tumbuhan. Karena itu, kita membutuhkan hubungan yang lebih intim, saling terhubung dengan segala sesuatu. ${ }^{66}$

Manusia bergantung pada kesehatan seluruh biosfer, seluruh ekosistem, seluruh biodiversitas dari semua mahkluk hidup. Degradasi biosfer, ekosistem, dan biodiversitas bukan hanya soal kerugian ekonomi atau masalah biaya, masalah keuntungan dan kerugian finansial semata. Hal itu adalah masalah proses pemiskinan kemanusiaan manusia terutama relasi spiritualitas dengan pencipta dan ciptaan, penurunan nilai ciptaan, mempersingkat keberlanjutan kehidupan bersama, dan pemiskinan nilai planet ini. ${ }^{67}$

\section{Kesimpulan}

Dari keseluruhan deskripsi pembahasan, beberapa hal dapat ditarik sebagai simpulan. Pertama, Alkitab dengan tegas mengatakan bahwa biodiversitas adalah ciptaan Allah yang memiliki nilai instrinsik.

65. Celia Deane-Drummond, "Laudato Si' and the Natural Sciences: An Assessment of Possibilities and Limits," Theological Studies 77, no. 2 (Juni 2016): 395-98, diakses 29 Oktober 2021, https://doi.org/10.1177/0040563916635118.

66. Bdk. Benedict XVI, The Garden of God, 118-21.

67. Bauckham, Living with Other Creatures, 232. 
Allah sendiri sangat mengapresiasi nilai intrinsik seluruh ciptaan-Nya serta nilai biodiversitas sebagai hasil karya kreatif-Nya. Dengan begitu, nilai intrinsik biodiversitas sama sekali tidak bergantung pada pemikiran atau akal manusia, melainkan pada Allah sebagai penciptanya.

Nilai seluruh ciptaan, seluruh biodiversitas, sangat dihargai dan diapresiasi oleh Allah sejak masa penciptaan. Apresiasi itu terwujud dalam tindakan pemeliharaan secara terus-menerus (cth. Mat. 6:25-26). Sebagai bagian dari komunitas global serta komunitas Kristen yang percaya pada Allah Alkitab, kita pun harusnya menjadi co-creator Allah yang memelihara dan memperjuangkan keberlanjutan biodiversitas, sebab biodiversitas itu milik Allah, karena milik Allah maka itu adalah suci (dedivinized).

Kedua, Alkitab menunjukkan bahwa biodiversitas sangat penting bagi keberlanjutan hidup manusia. Bukan hanya menjadi obat atau bahan kebutuhan pokok maupun pelengkap, biodiversitas juga menjadi sarana penting bagi manusia dalam menikmati Allah di bumi. Melalui sifat sakramental biodiversitas, orang Kristen maupun orang beragama/ kepercayaan lain ditolong untuk mengenal Allah.

Ketiga, karena biodiversitas memiliki sifat sakramental, degradasi ekologis dan kepunahan biodiversitas justru sedang merongrong, bahkan mengikis kemampuan manusia untuk mengenal, merasa, dan menyadari kehadiran Allah di bumi. Pembiaran terhadap degradasi dan kepunahan tersebut adalah sebuah kesalahan fatal; itu bagian dari dosa. Sebab sifat dosa pada dasarnya adalah menghambat pengenalan manusia akan Allah. 
Terakhir, sebagai kepala ciptaan ataupun co-creator Allah, pada dasarnya manusia sepenanggungan dengan alam, berkerabat dengan biodiversitas, tubuhnya (material) berasal dari yang alami, dari debu tanah. Ilusi egosentrisme para ekonom perlu dilawan dengan kembali menaikkan kemanusiaan kita dalam melihat biodiversitas. Bukan hanya menuntut apa yang harus alam atau biodiversitas berikan pada kita, tetapi "apa yang harus saya lakukan bagi alam dan biodiversitasnya," karena kita semua bergantung pada kesehatan biodiversitas yang berkualitas. Hal ini bukan hanya masalah untung rugi finansial, tetapi masalah kemanusiaan manusia, masalah keberlanjutan hidup bersama semua mahkluk bumi, dan masalah pemiskinan nilai planet ini. Perjuangan akan keberlanjutan biodiversitas pun niscaya dan sebenarnya adalah bagian yang tidak terpisahkan dari jati diri manusia itu sendiri, apalagi seorang Kristen.

\section{Daftar Pustaka}

\section{Buku}

Bauckham, Richard. Living with Other Creatures: Green Exegesis and Theology. Waco: Baylor University Press, 2011.

Copan, Paul. "Bioethics," dalam The Routledge Companion to Theism. Diedit oleh Charles Taliaferro, Victoria S. Harrison, dan Stewart Goetz. Edisi ke-1. New York: Routledge, 2012.

Davis, Ellen F. Scripture, Culture, and Agriculture: An Agrarian Reading of the Bible. Edisi ke-1. Cambridge: Cambridge University Press, 2008.

Eldredge, Niles, ed. Life on Earth: An Encyclopedia of Biodiversity, Ecology, and Evolution: Life on Earth. Santa Barbara: ABC-CLIO, 2002.

Gottlieb, Roger S. "Introduction: Religion and Ecology-What Is the Connection and Why Does It Matter?" dalam The Oxford Handbook of Religion and Ecology. Diedit oleh Roger S. Gottlieb. Edisi ke-1. Oxford: Oxford University Press, 2010. 
Lovejoy, Thomas E. "Biodiversity: An inordinate fondness for living things," dalam Routledge Handbook of Religion and Ecology. Diedit oleh Willis Jenkins, Mary Evelyn Tucker, dan John Grim. Edisi ke-1. New York: Routledge, 2018.

Maclaurin, James, dan Kim Sterelny. What Is Biodiversity? Edisi ke-1. Chicago: University of Chicago Press, 2008.

Nash, James. Loving Nature: Ecological Integrity and Christian Responsibility. Nashville: Abingdon, 1991.

O'Brien, Kevin J. An Ethics of Biodiversity: Christianity, Ecology, and the Variety of Life. Washington: Georgetown University Press, 2010.

Rogers, Heather. Green Gone Wrong: How Our Economy Is Undermining the Environmental Revolution. London: Verso, 2010.

Rolston, Holmes. "Environment," dalam The Routledge Companion to Theism. Diedit oleh Charles Taliaferro, Victoria S. Harrison, dan Stewart Goetz. Edisi ke-1. New York: Routledge, 2012.

Subdirektorat Statistik Lingkungan Hidup, ed. Statistik Lingkungan Hidup Indonesia 2019. Jakarta: Badan Pusat Statistik/BPS-Statistics Indonesia, 2019.

Supriatna, Jatna. Konservasi Biodiversitas: Teori dan Praktik di Indonesia. Jakarta: Yayasan Pustaka Obor Indonesia, 2018.

XVI, Pope Benedict. The Garden of God: Toward a Human Ecology. Washington: The Catholic University of America Press, 2014.

\section{Jurnal}

Childs, James M. Jr. "The Ecology of Moral Authority: A Response to James A. Nash, 'The Bible and Biodiversity: The Case against Moral Arguments from Scripture.'” Journal for the Study of Religion, Nature and Culture 3, no. 2 (Juni 2009): 254-259. Diakses 26 September 2020. http://search.ebscohost.com/login.aspx?

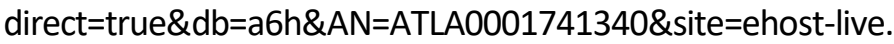

Conradie, Ernst M. "The Whole Household of God (Oikos): Some Ecclesiological Perspectives: Part 1." Scriptura: Journal for Biblical, Theological and Contextual Hermeneutics 94 (2007): 1-9. Diakses 22 Oktober 2021. https://scriptura.journals.ac.za/pub/article/ view/1431.

"The Whole Household of God (Oikos): Some Ecclesiological Perspectives (Part 2)." Scriptura: Journal for 
Biblical, Theological and Contextual Hermeneutics 94, no. 0 (2007): 10-28. Diakses 22 Oktober, 2021. https://scriptura. journals.ac.za/pub/article/view/1436.

Dafni, Amots, dan Barbara Böck. "Medicinal Plants of the BibleRevisited." Journal of Ethnobiology and Ethnomedicine 15, no. 1 (November 2019): 1-14. Diakses 22 Oktober 2021. https://doi.org/10.1186/s13002-019-0338-8.

Deane-Drummond, Celia. "Laudato $\mathrm{Si}^{\prime}$ and the Natural Sciences: An Assessment of Possibilities and Limits." Theological Studies 77, no. 2 (Juni 2016): 392-415. Diakses 29 Oktober, 2021. https://doi.org/10.1177/0040563916635118.

"Response to James A. Nash: 'The Bible vs. Biodiversity: The Case against Moral Argument from Scripture."' Journal for the Study of Religion, Nature and Culture 3, no. 2 (Juni 2009): 271-278. Diakses 26 September 2021. http://search. ebscohost.com/login.aspx?direct=true\&db=a6h\&AN=ATLA0001 741362\&site=ehost-live.

Hutagalung, Novriana Gloria. "Holy Grandeur Enough for All." GEMA TEOLOGIKA: Jurnal Teologi Kontekstual dan Filsafat Keilahian 2, no. 2 (Oktober 2017): 195-212. Diakses 25 Oktober 2021. http://journal-

theo.ukdw.ac.id/index.php/gemateologika/article/view/317.

Leese, J. J. Johnson. "Ecofaith: Reading Scripture in an Era of Ecological Crisis." Religions 10, no. 3 (Maret 2019): 1-13. Diakses 22 Oktober 2021. https://www.mdpi.com/2077-1444/10/3/154.

Murdiyarso, Daniel, et al. "Meninjau Kembali Kebijakan Alih-Guna Lahan dan Keberkelanjutan Sektor Sawit di Indonesia." Akademi IImu Pengetahuan Indonesia, no. 1 (2020): 1-4.

Nash, James. "The Bible vs. Biodiversity: The Case against Moral Argument from Scripture." Journal for the Study of Religion, Nature and Culture 3, no. 2 (Juni 2009): 213-237. Diakses 26 September 2021. http://search.ebscohost.com/login.aspx?direct=true\&db= a6h\&AN=ATLA0001741316\&site=ehost-live.

Pe'er, Guy, et al. "Adding Some Green to the Greening: Improving the EU's Ecological Focus Areas for Biodiversity and Farmers." Conservation Letters 10, no. 5 (2017): 517-530. Diakses 22 
Oktober 2021. https://onlinelibrary.wiley.com/doi/abs/10.1111 /conl.12333.

Ranboki, Buce A. "Menemukan Teologi Leonardo Boff Dalam Ensiklik Paus Fransiskus Laudato Si'." Indonesian Journal of Theology 5, no. 1 (Juli 2017): 42-67. Diakses 28 Oktober 2021. https://indo theologyjournal.org/index.php/home/article/view/34.

Zaluchu, Sonny Eli. "Metode Penelitian di dalam Manuskrip Jurnal IImiah Keagamaan." Jurnal Teologi Berita Hidup 3, no. 2 (Maret 2021): 249-266. Diakses 23 Desember 2021. https://e-journal. sttberitahidup.ac.id/index.php/jbh/article/view/93

\section{Website}

"Apa Yang Terjadi Pada Hutan Global Pada 2020? | Global Forest Watch Blog." Global Forest Watch Content. Last modified 31 Maret 2021. Diakses 19 Oktober 2021. https://www.globalforestwatch. $\mathrm{org} / \mathrm{blog} / \mathrm{id} /$ data-and-research/data-kehilangan-tutupan-pohon -global-2020.

"Arti Kata Analgesik-Kamus Besar Bahasa Indonesia (KBBI) Online." Diakses Oktober 2021. https://kbbi.web.id/analgesik.

"Badan Pusat Statistik." Diakses 19 Oktober 2021. https://www.bps. go.id/publication.html?Publikasi\%5BtahunJudul\%5D=\&Publikasi \%5BkataKunci\%5D=hutan\&Publikasi\%5BcekJudul\%5D=0\&yt0=T ampilkan.

Weisse, Mikaela, dan Elizabeth Goldman. "Kerusakan Hutan Hujan Primer Meningkat Sebesar 12\% Dari Tahun 2019 Hingga Tahun 2020 | WRI Indonesia." Last modified 1 April 2021. Diakses 19 Oktober 2021. https://wri-indonesia.org/id/blog/kerusakan-hutan-hujanprimer-meningkat-sebesar-12-dari-tahun-2019-hingga-tahun2020. 